\title{
The Use of Sports Apps for Engaging in Physical Activity
}

\author{
Silvija Baubonytė, Karolina Deliautaitė, Kristina Mejerytė Narkevičienė, Irena Valantinė \\ Lithuanian Sports University, Kaunas, Lithuania
}

\begin{abstract}
Background. As healthy lifestyle and physical activity become more relevant, sports apps are receiving more attention as one of the most convenient tools for monitoring one's physical condition. While activity-related apps are thought to be effective tools for health care and management, there is still a lack of information on the key factors that motivate individuals to download and use them. Seeing the large selection of different sports apps with similar functions, it can be assumed that other factors, such as certain characteristics of the apps or the user's characteristics can also influence the consumer's choice.

Methods. The study included 410 physically active subjects who were using sports apps (137 men and 273 women). To establish sports app usage, the questionnaire developed by Ha, Kang, and Ha (2015) was used. The statistical analysis of the data was performed using SPSS.

Results. In the analysis of different factors, the perception of sports apps was assessed the most positively. All these factors were more likely to be assessed positively by women than by men $(p \leq .05)$. The strongest correlations with intentions were found between perceptions of sports apps (enjoyment, ease of use, usefulness, reliability) $(r>.5$, $p \leq .01$ ) while with other variables correlations were slightly lower.

Conclusions. Women are more positive about the use of sports apps, in their perceptions and their connection to the smart device. Intentions to use sports apps are most influenced by perceptions of sports apps and personal innovativeness, which not only directly affects the intentions themselves, but also influences the perceptions that influence the intentions.
\end{abstract}

Keywords: smartphones, smart devices, sports involvement, innovation, perception.

\section{INTRODUCTION}

$\mathrm{T}$ The emergence of smart devices and the variety of apps in them, due to their ease of use and usage intensity, is becoming the most important thing in the daily life of today's consumers (Kim, Kim, \& Rogol, 2017). As a healthy lifestyle and physical activity become more relevant, smart sports apps are receiving more attention as one of the most convenient tools for monitoring physical activity (Lim \& Noh, 2017).

Previous research suggests that the use of sports apps is mainly influenced by the desire to track one's physical activity, change the concept of health care, and introduce or change an exercise regimen (Lin, Shen, Mao, \& Yang, 2019). While health-related apps are thought to be effective tools for health care and management there is still a lack of information on the key factors that motivate individuals to download and use such apps (Chen \& Lin, 2018). Seeing a large selection of different sports apps with similar functions, it can be assumed that various factors, such as certain characteristics of the apps or the users themselves, also influence the consumer's choice.

The main models investigating acceptance of the new technologies are the technology acceptance model (TAM) (Davis, 1989) and the sports websites acceptance model (SWAM) (Hur, Ko, \& Claussen, 2011). These models examine the acceptance of smart technologies through smart devices and sports-specific factors and have discovered that 
the use of apps is influenced by user perceptions of their ease of use (Herrmann \& Kim, 2017; Lee, Kim, \& Wang, 2017; Mohammadi \& Isanejad, 2018), usefulness (Alalwan et al., 2016; Herrmann \& Kim, 2017; Kim, Kim, \& Rogol, 2017), as well as the user's involvement in physical activity (Cheung, Or, So, \& Tiwari, 2018).

Studies show that people usually give priority to easy and useful activities, in case of which the experience with them tends to be viewed positively. Otherwise, if the activity is complicated, it will often be perceived as unpleasant and boring (Ha et al., 2017). Also, the ease of use of the apps is seen by the user as an advantage that helps to perform activities easily and comfortably, creates positive emotions, and stimulates the desire to continue using the application (Cho \& Kim, 2015). The more positive users evaluate the ease of using the more benefits they see in the app (Cho \& Kim, 2015).

Other research suggests that user choices may be influenced not only by previously considered factors such as perceived ease of use and usefulness of the apps but also by the perceived enjoyment (Byun, Chiu, \& Bae, 2018; Lee et al., 2017) and perceived trust (Kim et al., 2017). The study suggests that the more enjoyment users perceived in the sports app, the more benefits they see in it (Cho \& Kim, 2015). If the user trusts the information provided by the app, they often tend to think that the app used is useful (Cho \& Kim, 2015).

It is also well established that the personal characteristics of users themselves, such as attachment to smart devices (Ha, Kang, \& Kim, 2017) or innovativeness, can also determine the desire to try new technologies (Anwar, Thongpapanl, \& Ashraf, 2020; Dhiman, Arora, Dogra, \& Gupta, 2019; Jeon, Ali, \& Lee, 2019). According to researchers, innovativeness is one of the most important personality traits that determines the desire to try new technologies (Kim et al., 2017; Okumus, Ali, Bilgihan, \& Ozturk, 2018). Therefore, researchers Ha, Kang, and Ha (2015) have developed an improved version of the model that focuses not only on commonly considered important factors but more broadly examines the factors that stimulate intentions to use sports apps. As this model extensively examines the adoption of smart devices using it, we aim to elucidate the use of sports apps through their perception, personal user characteristics, and relationship with the smart device.

\section{METHODS}

Research methods. The research used a questionnaire developed by $\mathrm{Ha}$, Kang, and Ha (2015), which consisted of several parts determination of physical activity, usage of sports apps, user innovativeness, attachment to a smart device, the need for interaction, perception of sports apps (usefulness, ease of use, pleasure, and reliability) and further intentions to use the apps. Each of the factors had several questions which had to be evaluated using a 5-point Likert scale from 1 (totally disagree) to 5 (totally agree).

Subjects. The questionnaire was completed by 411 respondents. One was excluded from the study as ineligible, and the remaining 410 responses were used for further analysis of the results. To participate in the study, the following inclusion criteria for participants were considered: (1) to be physically active and (2) to use sports apps. The demographic characteristics of the subjects that participated in the survey are provided in the Table.

Table. The demographic characteristics of the subjects

\begin{tabular}{|l|l|c|c|}
\hline \multirow{3}{*}{ Gender } & & Subjects $(n)$ & Per cent (\%) \\
\cline { 2 - 4 } & Wen & 137 & $33.4 \%$ \\
\hline \multirow{4}{*}{ Age } & $18-23$ & 273 & $66.6 \%$ \\
\cline { 2 - 4 } & $24-29$ & 207 & $37.3 \%$ \\
\cline { 2 - 4 } & $30-35$ & 36 & $50.5 \%$ \\
\cline { 2 - 4 } & $36-40$ & 7 & $8.8 \%$ \\
\cline { 2 - 4 } & $41+$ & 7 & $1.7 \%$ \\
\hline \multirow{2}{*}{ Total } & & 410 & $100 \%$ \\
\hline
\end{tabular}

Statistical analysis. The obtained data were systematised and processed by statistical data analysis using SPSS 26.0 (Statistical Package for the Social Sciences) program. The Cronbach Alpha criteria were calculated to assess the reliability of the questionnaire, and showed that the internal reliability of the questionnaire was high and usable $(\alpha=.950 ; n=46)$. Nonparametric data analysis based on the Kolmogorov-Smirnov test was used to determine the differences in results between the groups, the difference in sizes was significant when $p \leq .05$. Spearman's correlation coefficient was used to determine the relationship of data that did 
not match the normal distribution coefficient, the relationship was significant when $p \leq .05$.

\section{RESULTS}

As the most common reason for using sports apps is the promotion and monitoring of physical activity, the participants were subject to a physical activity condition. The duration of physical activity (in years) and the main motives for it were determined during the study.

It was found that the majority of subjects were physically active for 3-6 (35.4\%), 1-3 (24.6\%), and 6-10 years $(21.7 \%)$, and the main motives for physical activity were identified as self-improvement $(96.8 \%)$, the pursuit of better shape $(96.2 \%)$, health reasons $(93.1 \%)$, relaxation $(89.2 \%)$, fun $(80.2 \%)$ and love of sport (78.2\%). Assessing the use of sports apps, it was found that the majority of respondents had 1-2 (64.4\%) or $3-4(30 \%)$ sports apps on their smartphones, which they used 1-3 times a week (40.7\%) or once daily $(36.8 \%)$. The greatest benefits from sports apps were reported as information on physical activity (4.64), physical activity results (4.63), and physical activity control (4.60).

To find out the factors influencing the use of sports apps in the research, we identified user innovativeness, the need for interaction, personal attachment, and perceptions of sports apps (5-point
Likert scale). The results showed that the most positively assessed perceptions of sports apps were ease of use (4.64), usefulness (4.56), reliability (4.12), and enjoyment (3.83). User characteristics and behavioural peculiarities such as attachment to smart devices (3.35), the need for interaction (3.24), and innovativeness (2.60) were rated as relatively average. All of these factors, except for the need for interaction, tended to be assessed more positively by women than men $(p \leq .05)$.

Correlation analysis was performed to determine the factors influencing the intentions to use the sports apps usage. The obtained results are shown in the Figure.

The obtained results show that the greatest connection is between intentions and the perceptions of sports apps - usefulness $(r=.698$, $p \leq .01)$, trust $(r=.626, p \leq .01)$, enjoyment $(r=.575$, $p \leq .01)$ and ease of use $(r=.539, p \leq .01)$. Perceptions have also been found to affect not only intentions but also each other. The strongest correlations were found between perceived usefulness with other perceptions - perceived ease of use $(r=.524$, $p \leq .01)$, reliability $(r=.614 ; p \leq .01)$ and perceived enjoyment $(r=.634, p \leq .01)$, and between perceived reliability and perceived enjoyment $(r=.614$, $p \leq .01)$. Weaker but also significant relationships were found between ease of use and enjoyment $(r=.401, p \leq .01)$ and trust $(r=.442, p \leq .01)$.

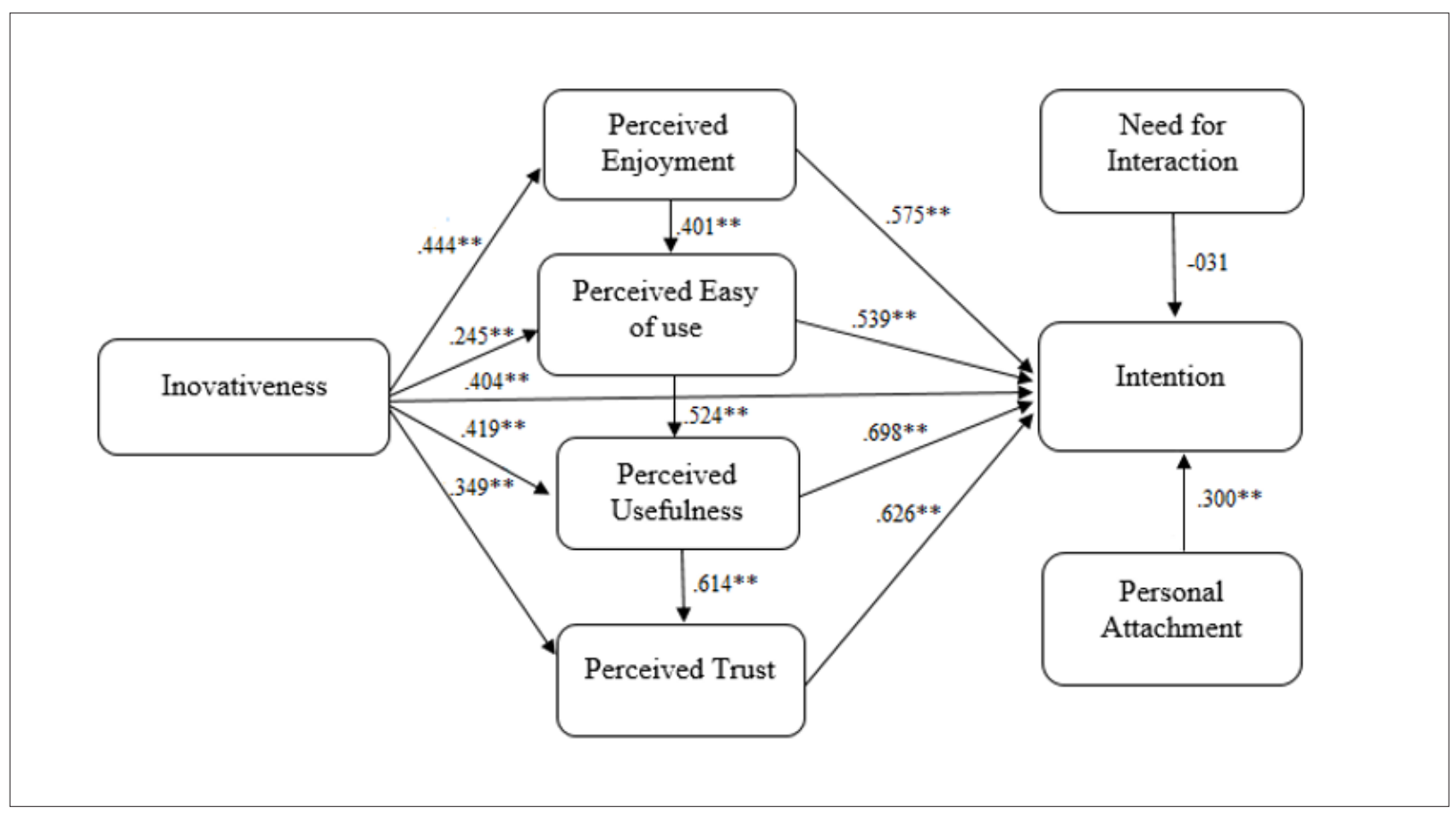

Figure. Correlations between user innovativeness, apps perception, personal attachment, and the need for interaction with intentions to use sports apps 
Assessing the relationship between user characteristics and behavioural peculiarities and further intentions, the highest relationship was found between personal consumer innovativeness and intentions $(r=.404, p \leq 0.01)$. Innovativeness also correlated with perceptions of sports apps - perceived pleasure $(r=.444, p \leq .01)$, perceived usefulness $(r=.419, p \leq .01)$, reliability $(r=.349, p \leq .01)$ and perceived ease of use $(r=.249$, $p \leq .01)$. Personal attachment had a significant positive effect on intentions to use sports apps, but this association was weak $(r=.3, p \leq .01)$. There was an inverse very weak correlation between the need for interaction and intentions $(r=-.031)$, but it was not statistically significant $(p>.05)$.

\section{DISCUSSION}

In this study, we sought to elucidate the factors influencing the use of sports apps while engaging in physical activity, identifying user innovativeness, attachment to a smart device, the need for interaction, perceptions of sports apps, intentions to use them, and the relationship between all these factors.

The results of the study revealed that sports apps users tended to view their perceptions positively, but also to question their innovativeness and behavioural characteristics such as the need for interaction or the need for human interaction. We also found that women tended to be more positive about perceptions of sports apps, innovativeness, and the need for interaction, as well as further intentions to use sports applications. This is inconsistent with studies by other researchers that have found that gender is irrelevant to technology acceptance (Sánchez-Mena, Martí-Parreño \& Aldás-Manzano, 2019; Sindermann, C., Riedl, \& Montag, 2020), or that men have a closer relationship with smart devices and apps and therefore value them more positively (Teo, 2010; Whitehead, Umeh, Quayle, \& Morley, 2017).

The results of our research showed that perceived ease of use has a positive relationship with perceived usefulness and enjoyment. This is consistent with the findings of other researchers that users who perceive apps usage as easy tend to evaluate their usefulness (Alalwan, Dwivedi, Rana, \& Williams, 2016; Liu \& Yu, 2017) and pleasure (Ashrafi et al., 2016; Byun et al., 2018) positively. People usually give priority to easy and useful activities, in case of which the experience in them tends to be viewed positively. Otherwise, if the activity is complicated, it will often be perceived as unpleasant and boring (Ha et al., 2017). The study also confirmed the findings of researchers Cho and Kim (2015) that ease of use of the apps is seen by the user as an advantage that helps to perform activities easily and comfortably, creates positive emotions, and stimulates the desire to continue using the application. The study also revealed that perceptions of usefulness have the greatest connection to perceived pleasure, reliability, and ease of use. This is also consistent with the results of a study by researchers Cho and Kim (2015), which showed a link between utility and other perceptions. The more positively users evaluate the ease of use and enjoyment, the more benefits they see in the app. If the user trusts the information provided by the app, they often tend to think that the app used is useful (Cho \& Kim, 2015).

According to researchers, innovativeness is one of the most important personality traits that determine the desire to try new technologies, and it is one of the key characteristics that determine the use of sports apps (Anwar, Thongpapanl, \& Ashraf, 2020; Dhiman et al., 2019; Jeon, Ali, \& Lee, 2019; Kim et al., 2017; Okumus, Ali, Bilgihan, \& Ozturk, 2018). Among the personal characteristics analysed in the study, the correlation between innovativeness and intentions was the largest. It was also confirmed that this was one of the most important characteristics of a person. Observing the relationship between innovativeness and perception of sports apps, it was found that innovative users tended to appreciate the perceived pleasure and benefits of sports apps, so it cannot confirm the results of a previous study that innovativeness related to perceived ease of use the most (Kuo \& Yen, 2009). In the study, it was identified that more innovative users tended to be more positive about the perceived enjoyment and usefulness of sports apps, and only then about the intentions. This is partly confirmed by the other research results that consumers' characteristics such as innovativeness determined not only the use of apps, but such users were also more positive about innovations and were open to recommendations (San Martín \& Herrero, 2012; Tussyadiah, 2016).

Following the results of the study, consumers tended to rate their attachment on average. The study showed that the more a person personalised their smartphones, the more time they spent on them, which in turn increased the use (Ha et al., 
2017). The results of the study also confirmed this only partially. Personal attachment to smartphones had a significant relationship with intentions to use sports apps, but the relationship was weak. Such results suggest that the subjects themselves did not show a high level of attachment. Perhaps a higher level of attachment would also have predicted a stronger connection with intentions.

The results of our research showed that consumer intentions were mostly related to perceptions of trust and usefulness. This is consistent with the findings of other researchers who suggest that consumer intentions are determined by the perceived usefulness of sports apps (Alalwan et al., 2016; Herrmann \& Kim, 2017; Kim, Kim, \& Rogol, 2017), and reliability (Kim et al., 2017). Other studies suggest that the most important determinants of intent are perceived ease of use (Herrmann \& Kim, 2017; Ha, Kang, \& Kim, 2017; Lee, Kim, \& Wang, 2017; Mohammadi \& Isanejad, 2018), and perceived pleasure (Byun, Chiu, \& Bae, 2018; Lee et al, 2017). The results of the study also showed that these factors were significant and related to intentions, but they were not the most important. The use of sports apps is driven by the user's intentions, which are determined by their formed attitudes. Thus, the more positive the consumer's attitude towards the sports application, the greater the intentions to use it is (Mohammadi \& Isanejad, 2018).

\section{CONCLUSIONS}

The perceptions of sports applications are appreciated the most. Because of innovativeness and personal attachment, the consumer is often doubtful, and the need for interaction is seen more negatively than positively. Women are more positive about the use of sports apps in their perceptions and their connection to the smart device.

The research leads to the conclusion that intentions to use sports applications are most influenced by perceptions of it - ease of use, usefulness, reliability, and enjoyment, which not only directly affect intentions, but also affect each other. Personal innovativeness and personal attachment relationships with intentions are similar, but innovativeness still affects perceptions that are one among the most important for further intentions. The need for interaction is not related to intentions to use sports applications.

\section{REFERENCES}

Alalwan, A. A., Dwivedi, Y. K., Rana, N. P., \& Williams, M. D. (2016). Consumer adoption of mobile banking in Jordan. Journal of Enterprise Information Management, 29(1), 118-139. https://doi.org/10.1108/ JEIM-04-2015-0035

Anwar, A., Thongpapanl, N., \& Ashraf, A. R. (2020). Strategic imperatives of mobile commerce in developing countries: the influence of consumer innovativeness, ubiquity, perceived value, risk, and cost on usage. Journal of Strategic Marketing, 1-21. https://doi.org/10. 1080/0965254X.2020.1786847

Ashrafi, S. H. R., Poursoltani, H., \& Ghareh, M. A. (2016). The relationship between some perceived aspects of information and communication technology with sports community training of Khuzestan province. International Journal of Pharmaceutical Research \& Allied Sciences, 5(3), 108-112.

Byun, H., Chiu, W., \& Bae, J. S. (2018). Exploring the adoption of sports brand apps: An application of the modified technology acceptance model. International Journal of Asian Business and Information Management, 9(1), 52-65. doi: 10.4018/IJABIM.2018010105

Chen, M. F., \& Lin, N. P. (2018). Incorporation of health consciousness into the technology readiness and acceptance model to predict app download and usage intentions. Internet Research, 28(2), 351-373. https:// doi.org/10.1108/IntR-03-2017-0099
Cheung, D. S. T., Or, C. K. L., So, M. K. P., \& Tiwari, A. (2018). Usability testing of a smartphone application for delivering Qigong training. Journal of Medical Systems, 42(10), 191. https://doi.org/10.1007/s10916-018-1048-9 Cho, J., \& Kim, S. J. (2015). Factors of leading the adoption of diet/exercise apps on smartphones: Application of Channel Expansion Theory. Journal of Internet Computing and Services, 16(1), 101-108. https://doi.org/10.7472/jksii.2015.16.1.101

Davis, F. D. (1989). Perceived usefulness, perceived ease of use, and user acceptance of information technology. MIS Quarterly, 13(3), 319-340. https://doi. org/10.2307/249008

Dhiman, N., Arora, N., Dogra, N., \& Gupta, A. (2019). Consumer adoption of smartphone fitness apps: an extended UTAUT2 perspective. Journal of Indian Business Research, 12(3), 363-388. https://doi. org/10.1108/JIBR-05-2018-0158

Ha, J. P., Kang, S. J., \& Ha, J. (2015). A conceptual framework for the adoption of smartphones in a sports context. International Journal of Sports Marketing \& Sponsorship, 16(3), 2-19. https://doi.org/10.1108/ IJSMS-16-03-2015-B002

Ha, J. P., Kang, S. J., \& Kim, Y. (2017). Sport fans in a "smart sport" (SS) age: Drivers of smartphone use for sport consumption. International Journal of Sports 
Marketing and Sponsorship, 18(3), 281-297. https://doi. org/10.1108/IJSMS-08-2017-093

Herrmann, L. K., \& Kim, J. (2017). The fitness of apps: a theory-based examination of mobile fitness app usage over 5 months. Mhealth, 3(2), 1-9. https://dx.doi.org/10. 21037\%2Fmhealth.2017.01.03

Hur, Y., Ko, Y. J., \& Claussen, C. L. (2011). Acceptance of sports websites: A conceptual model. International Journal of Sports Marketing \& Sponsorship, 12(3), 1327. https://doi.org/10.1108/IJSMS-12-03-2011-B003

Jeon, H. M., Ali, F., \& Lee, S. W. (2019). Determinants of consumers' intentions to use smartphones apps for flight ticket bookings. The Service Industries Journal, 39(5-6), 385-402. https://doi.org/10.1080/02642069.20 18.1437908

Kim, Y., Kim, S., \& Rogol, E. (2017). The effects of consumer innovativeness on sport team applications acceptance and usage. Journal of Sport Management, 31(3), 241-255. https://doi.org/10.1123/jsm.2015-0338

Kuo, Y. F., \& Yen, S. N. (2009). Towards an understanding of the behavioral intention to use $3 \mathrm{G}$ mobile value-added services. Computers in Human Behavior, 25(1), 103110. https://doi.org/10.1016/j.chb.2008.07.007

Lee, S., Kim, S., \& Wang, S. (2017). Motivation factors influencing intention of mobile sports apps use by applying the unified theory of acceptance and use of technology (UTAUT). International Journal of Applied Sports Sciences, 29(2), 115-127. https://doi. org/10.24985/ijass.2017.29.2.115

Lim, J. S., \& Noh, G. Y. (2017). Effects of gain-versus loss-framed performance feedback on the use of fitness apps: Mediating role of exercise self-efficacy and outcome expectations of exercise. Computers in Human Behavior, 77, 249-257. https://doi.org/10.1016/j.chb.2017.09.006

Lin C.T., Shen C.C., Mao T.Y., \& Yang C.C. (2019). Empirical investigation of sports management, behavior growth and usage of sports app: new learning perspective. Polish Journal of Management Studies, 19(1), 225-234. http://dx.doi.org/10.17512/pjms.2019.19.1.17

Liu, N., \& Yu, R. (2017). Identifying design feature factors critical to acceptance and usage behavior of smartphones. Computers in Human Behavior, 70, 131142. https://doi.org/10.1016/j.chb.2016.12.073

Mohammadi, S., \& Isanejad, O. (2018). Presentation of the Extended Technology Acceptance Model in Sports Organizations. Annals of Applied Sport Science, 6(1), 75-86. http://aassjournal.com/article-1-503-en.html

Okumus, B., Ali, F., Bilgihan, A., \& Ozturk, A. B. (2018). Psychological factors influencing customers' acceptance of smartphone diet apps when ordering food at restaurants. International Journal of Hospitality Management, 72, 67-77. https://doi.org/10.1016/j. ijhm.2018.01.001

San Martín, H., \& Herrero, Á. (2012). Influence of the user's psychological factors on the online purchase intention in rural tourism: Integrating innovativeness to the UTAUT framework. Tourism Management, 33(2), 341-350. https://doi.org/10.1016/j.tourman.2011.04.003 Sánchez-Mena, A., Martí-Parreño, J., \& AldásManzano, J. (2019). Teachers' intention to use educational video games: The moderating role of gender and age. Innovations in Education and Teaching International, 56(3), 318-329. https://doi.org/10.1080/14703297.2018. 1433547

Sindermann, C., Riedl, R., \& Montag, C. (2020). Investigating the Relationship between Personality and Technology Acceptance with a Focus on the Smartphone from a Gender Perspective: Results of an Exploratory Survey Study. Future Internet, 12(7), 110. https://doi. org/10.3390/fi12070110

Teo, T. (2010). Establishing gender structural invariance of technology acceptance model (TAM). AsiaPacific Education Researcher, 19(2), 311-320. http:// researchrepository.murdoch.edu.au/id/eprint/48589

Tussyadiah, I. P. (2016). The influence of innovativeness on on-site smartphone use among American travelers: Implications for context-based push marketing. Journal of Travel \& Tourism Marketing, 33(6), 806-823. https:// doi.org/10.1080/10548408.2015.1068263

Whitehead, A. E., Umeh, F. K., Quayle, L., \& Morley, D. (2017). Mobile technology usage mediates gender differences in physical activity. International Journal of Sport Psychology, 48(6). http://www.ijsp-online.com/ abstract/view/48/643 